\title{
Stress Concentration and Material Failure during Coiling of Ultra-Thin TRAC Booms
}

\author{
Christophe Leclerc* ${ }^{*}$ Antonio Pedivellano ${ }^{\dagger}$ and Sergio Pellegrino ${ }^{\ddagger}$ \\ California Institute of Technology, Pasadena, CA, 91125
}

\begin{abstract}
Ultra-thin TRAC booms are a promising technology for large deployable structures for space applications. A manufacturing process producing composites TRAC booms with flange thickness as low as $53 \mu \mathrm{m}$ is proposed. Coiling behavior around hub with radii ranging from $19.1 \mathrm{~mm}$ to $31.8 \mathrm{~mm}$ is studied both experimentally and through finite element simulations. Due to the thinness of the TRAC boom, a buckle appears in the inner flange, in the transition region from the fully deployed to the coiled configurations. Material failure is observed at this location, and this correlates well with stresses computed in simulation, coupled with the fiber microbuckling failure criterion. Reducing the thickness, either by changing the laminate or by improving the manufacturing process, is shown to reduce stresses, allowing coiling around smaller hubs without material failure.
\end{abstract}

\section{Nomenclature}

$L \quad$ Boom length

$R \quad$ Hub radius

$r \quad$ Flange radius of curvature

$t \quad$ Flange thickness

$w \quad$ Bonded region width

$\gamma_{y} \quad$ Yield shear strain

$\Delta \kappa_{x}$ Change of curvature in the longitudinal direction

$\Delta \kappa_{y}$ Change of curvature in the transverse direction

$\theta \quad$ Flange opening angle

$\sigma_{x x} \quad$ Normal stress in the longitudinal direction

$\sigma_{y y}$ Normal stress in the transverse direction

$\sigma_{x y} \quad$ In-plane shear stress

$\tau_{y} \quad$ Yield shear strength

$\bar{\phi} \quad$ Fiber misalignment angle

\section{Introduction}

The Triangular Rollable And Collapsible (TRAC) boom is a coilable structure originally developed by the Air Force Research Laboratory. ${ }^{1}$ Its cross-section consists of two tape springs bonded together along one edge, creating a thick web and two flanges. Due to their low mass, high packaging efficiency, high bending stiffness and ability to self-deploy, TRAC booms are key elements of multiple satellite designs, ${ }^{2,3}$ and were used to deploy solar sails on both NASA's Nanosail-D2 ${ }^{4,5}$ and Planetary Society's LightSail-A. ${ }^{6}$

Figure 1 shows the TRAC boom cross-section. The main geometric parameters are the flange radius of curvature $r$, thickness $t$, opening angle $\theta$ and the bonded section (web) width $w$. Once the flanges are

\footnotetext{
*Graduate Student, Graduate Aerospace Laboratories, 1200 E California Blvd. MC 205-45. AIAA Student Member. e-mail: cleclerc@caltech.edu

${ }^{\dagger}$ Graduate Student, Graduate Aerospace Laboratories, 1200 E California Blvd. MC 205-45. e-mail: apedivel@caltech.edu

$\ddagger$ Joyce and Kent Kresa Professor of Aeronautics and Professor of Civil Engineering, Graduate Aerospace Laboratories, 1200 E California Blvd. MC 105-50. AIAA Fellow. e-mail: sergiop@caltech.edu
} 
flattened, the boom can be coiled around a cylindrical hub of radius $R$.

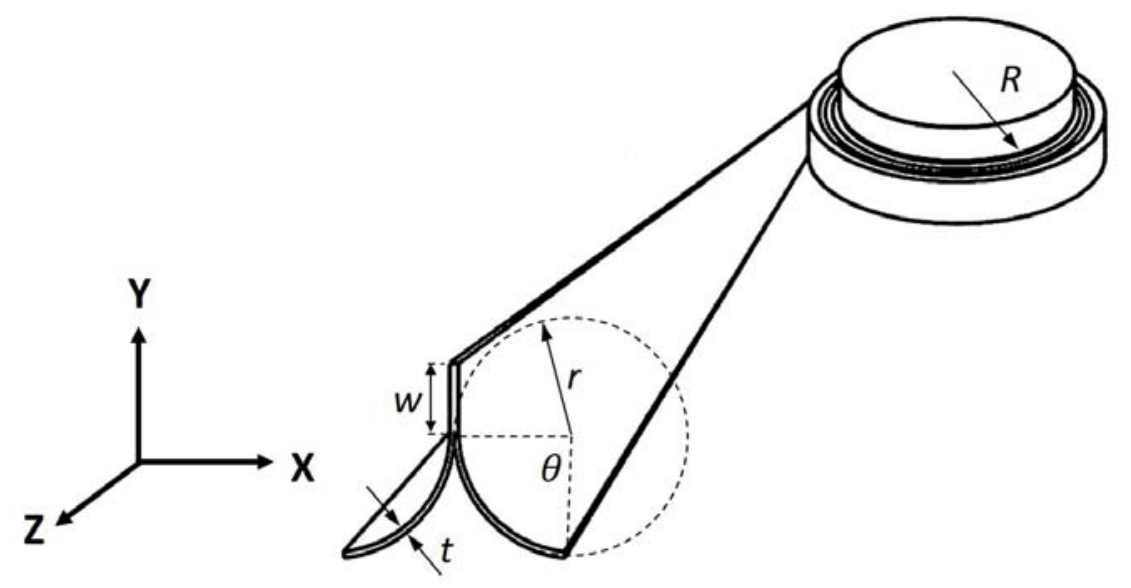

Figure 1. TRAC boom architecture (modified from Banik and Murphey ${ }^{7}$ ).

Initial research on TRAC booms studied structures made of both metals and composites materials. ${ }^{1,7}$ However, the flange thickness obtained with composite materials $(\sim 1 \mathrm{~mm})$ prevented the coiling radius to be small enough to fit in a Cubesat. For this reason, metallic TRAC booms were used both on Nanosail-D2 and LightSail-A. This led to concerns about in-orbit thermal effects, and it was shown that carbon fiber composite materials could reduce thermal deflections by a factor of 10 while retaining good axial load capability. ${ }^{8}$

More recently, TRAC booms made of thin-ply composites were studied, enabling tighter packaging and wider range of applications. ${ }^{9-12}$ The mechanical behavior in the deployed configuration was well characterized for TRAC booms with flange thickness as low as $71 \mu \mathrm{m}$, and energy considerations due to change in curvature of the web and both flanges were used to explain inner flange bifurcation and natural localized bend radius. Furthermore, Murphey et al ${ }^{10}$ observed stress concentration when inner flange buckling occurs during coiling. However, this work was limited to the region where the boom is already rolled, and did not investigate the transition region from the fully deployed configuration to the packaged configuration.

This paper focuses on the coiling behavior of ultra-thin TRAC booms, looking at inner flange instabilities within the transition region and the resulting stress concentration. More specifically, the effect of the cylindrical hub radius and the stacking sequence of the composite boom on cracking and failure during packaging are investigated.

First, a manufacturing process enabling fabrication of the desired shape is introduced. Next, an experimental setup allowing controlled coiling of TRAC booms is presented, followed by the experimental results. Then, a numerical modeling of the coiling process is described, with the objective of predicting the stress distribution in the structure, and the results of the numerical simulation are discussed. Finally, experimental and numerical results are compared, discussing the role of manufacturing-induced imperfections on the stress concentration.

\section{Manufacturing}

TRAC booms are traditionally manufactured in two steps, with the flanges fabricated first, followed by a bonding step along the web. A new method was developed, ${ }^{9}$ where flanges are co-cured together, removing the need for the second step. The material used is a unidirectional prepreg tape made of carbon fibers (Torayca T800) and an epoxy resin (NTPT ThinPreg 402). It is manufactured by North Thin Ply Technology using tow-spreading. This material has an dry areal mass of 17 GSM, leading to a ply thickness of $\sim 18 \mu \mathrm{m}$.

The full manufacturing process is illustrated in Figure 2. First, the desired layup is wrapped over two U-shaped aluminum molds. Second, the two molds are clamped together using multiple bolts, joining and pressing the two flanges. A silicone plug with a $V$ shape is added, allowing pressure to be applied along the $V$-groove, and also helping to form the flange merging point. The silicone used is Smooth-On's Mold Max XLS II, chosen due to its very low shrinkage during cure. Then, a vacuum bag encloses the full assembly and 
curing is done in autoclave. Finally, extra material is removed and the resulting TRAC boom is obtained.

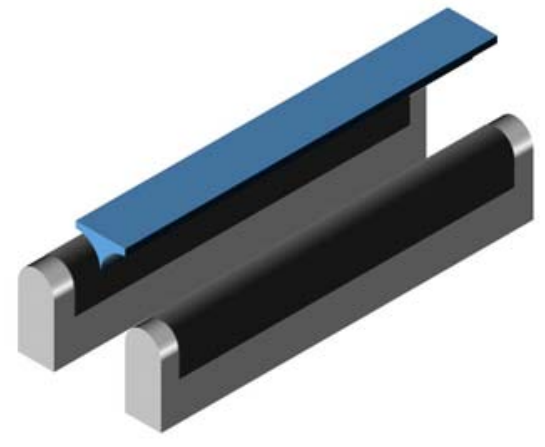

(a) Exploded view

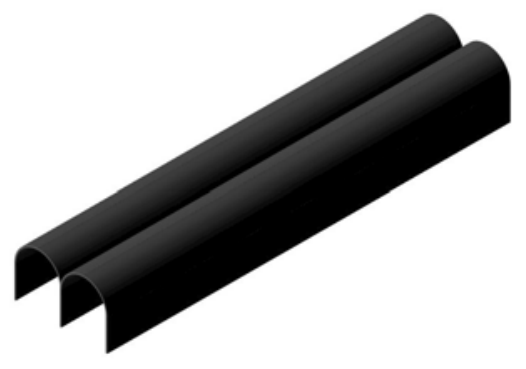

(c) Cured part

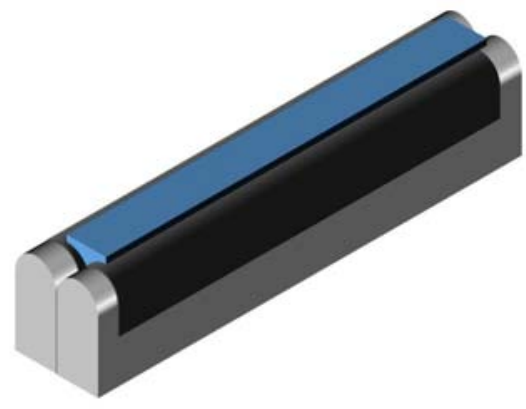

(b) Curing configuration

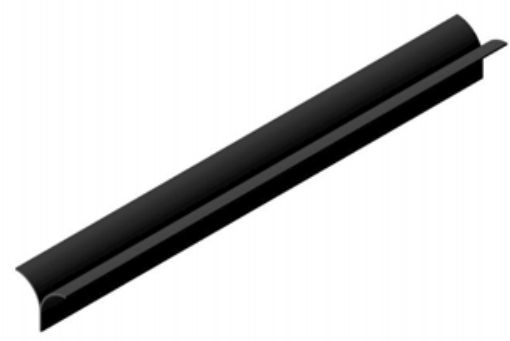

(d) Final structure

Figure 2. TRAC boom manufacturing process.

Two different layups were studied: $[0 / 90]_{S}(t=71 \mu \mathrm{m})$ and $[0 / 90 / 0](t=53 \mu \mathrm{m})$. The nominal geometric parameters are: $r=12.5 \mathrm{~mm}, \theta=90^{\circ}, w=8 \mathrm{~mm}$, and the length of the TRAC boom is $L=540 \mathrm{~mm}$. However, due to thermal effects during curing process, significant shape distortion occurs when TRAC booms are removed from their molds, mainly in the form of a spring-in of both flanges. Therefore, the resulting test samples exhibit the following dimensions: $r=10.6 \mathrm{~mm}, \theta=105^{\circ}$ and $w=8 \mathrm{~mm}$.

\section{Coiling Experiments}

\section{III.A. Experimental Setup}

A dedicated experimental setup for coiling TRAC booms was designed and can be seen in Figure 3. It consists of a cylindrical hub made of transparent acrylic, attached to a gearbox (Ondrive P30-60) with a 60:1 ratio. An electric motor drives the gearbox at $60 \mathrm{RPM}$, turning the hub at only $1 \mathrm{RPM}$. Three different hub radii can be used: $19.1 \mathrm{~mm}, 25.4 \mathrm{~mm}$ and $31.8 \mathrm{~mm}(0.75 ", 1 "$ and $1.25 ")$. The TRAC cross-section is flattened and attached on the hub using a narrow, flat clamp, as seen in Figure 4(a). A constant tension force is applied at the other end of the boom using a pulley. This force is applied using a "L" shaped clamp that is attached to the web only, as shown in Figure 4(b). This leaves the end section free to deform, and aligns the force with the centroid of the cross-section. Three cameras were used to observed the test: one camera looks from above, one camera positioned on the side (looking in -Y direction, at the web), and the other camera observing the inner flange from below (with an angle to avoid looking through the hub).

Preliminary testing showed that the inner flange can be unstable during coiling when the tension force is small (less than $5 \mathrm{~N}$ ). Increasing the tension force to $15 \mathrm{~N}$ greatly reduced the instability, leading to a coiling experiment that runs at a steady state. Also, a tension force is necessary to ensure that the flattened boom conforms well to the hub once packaged, preventing the inner flange from buckling or bifurcating once coiled. As a result, the tension force was kept constant at $15 \mathrm{~N}$ for all the experiments.

Each sample was first coiled around the largest radius $(R=31.8 \mathrm{~mm})$. Because of the thickness of the clamp, the boom can only be wrapped once around the hub. Once the boom was coiled, the experiment was stopped, and then the boom was uncoiled in a controlled way at the same rotational velocity. Next, coiling was repeated on the second hub $(R=25.4 \mathrm{~mm})$. If cracking occurred during the first test, the other end of 


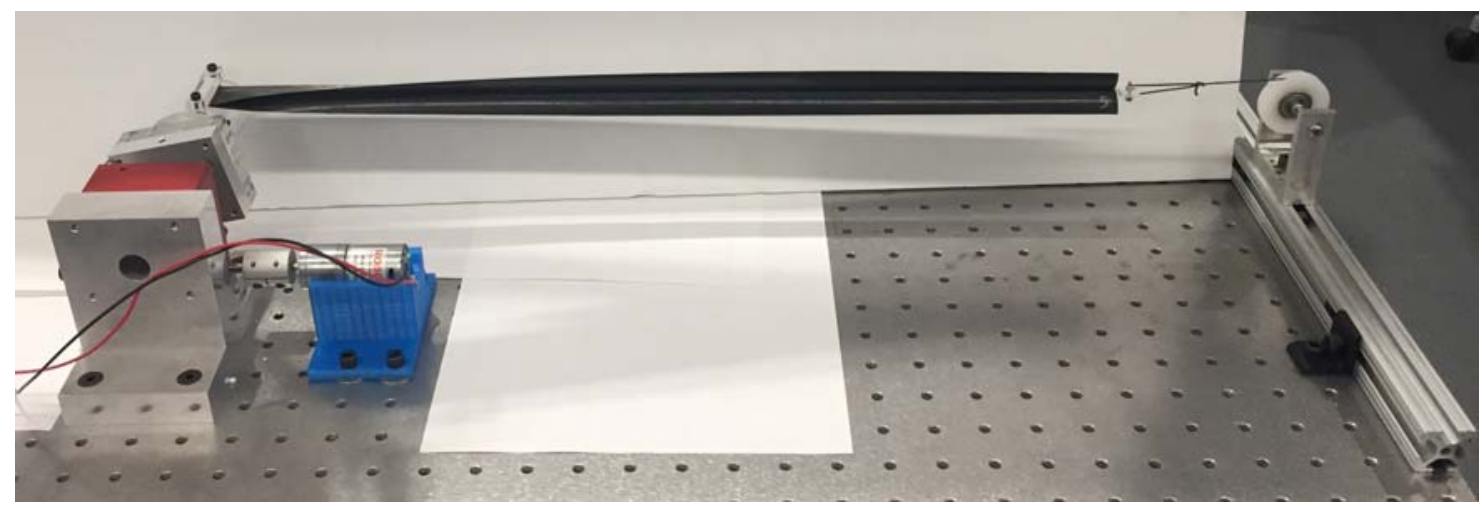

Figure 3. Coiling experimental setup.

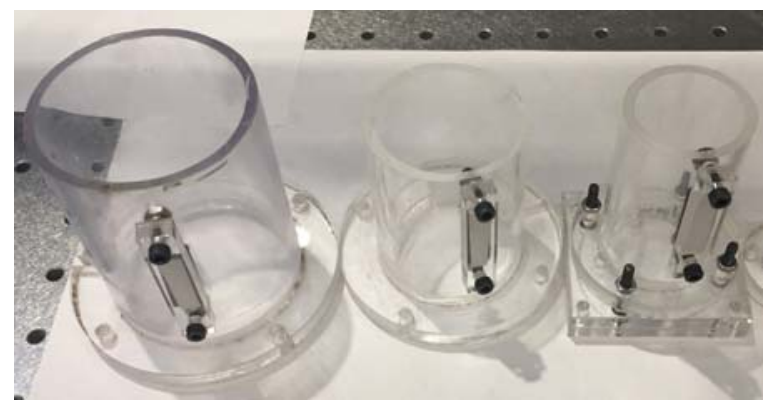

(a) 3 different hub radii: $31.8 \mathrm{~mm}, 25.4 \mathrm{~mm}, 19.1 \mathrm{~mm}$ (from left to right)

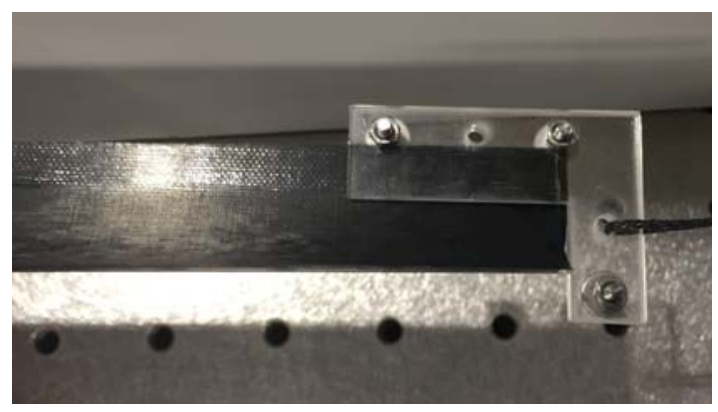

(b) Clamp applying tension force to the TRAC boom

Figure 4. Boundary conditions during coiling.

the sample was used for the next diameter. If no failure was observed, the same end was reused. Finally, if no cracking occurred at the biggest radius, the smallest radius $(R=19.1 \mathrm{~mm})$ was also tested. Inspection for cracks was done through visual examination. If a cracking sound was heard during the test, video was used to correlate the sound with the potential failure location, and a more thorough inspection was done under microscope. While this method is useful to find cracks on the outer surface, it does not allow detection of material failure in any of the inner plies of the laminates.

\section{III.B. Experimental Results}

Three samples with a $[0 / 90]_{S}$ layup were tested first (samples 4-1, 4-2 and 4-3). For all samples, the flattened boom complies very well to the hub in the coiled region for all radii. However, despite applying significant tension force, the inner flange exhibits instabilities in the transition region from fully deployed to coiled. The most common outcome from this instability is a bulging out of the inner flange, starting at the merging point of the flanges to the web. This kink initiates where the two flanges are flattened together and propagate roughly at $45^{\circ}$ outward in the transition region toward the free edge of the inner flange. This phenomenon is shown in Figure 5. High curvature can be observed locally at the tip (in the merging region), leading to a local stress concentration.

During the experiments, it was observed that this instability, and the related stress concentration, often lead to material failure. In the case of the 4-ply samples, two of the three booms (4-2 and 4-3) exhibited failure during coiling around the hub with the biggest radius. The failure mechanism that was observed experimentally is cracking of the outer ply ( $0^{\circ}$ orientation) of the inner flange. Cracks are starting at the merging region and propagate transversely over a distance of about $2 \mathrm{~mm}$.

In the case of boom 4-1, no cracks were observed after coiling around the $31.8 \mathrm{~mm}$ hub. One crack was found after coiling around the $25.4 \mathrm{~mm}$ hub, and multiple cracks (at least 5) appeared during coiling around the smaller hub.

Boom 4-2 displayed 7 cracks following coiling around the bigger hub, and multiple cracks after packaging 


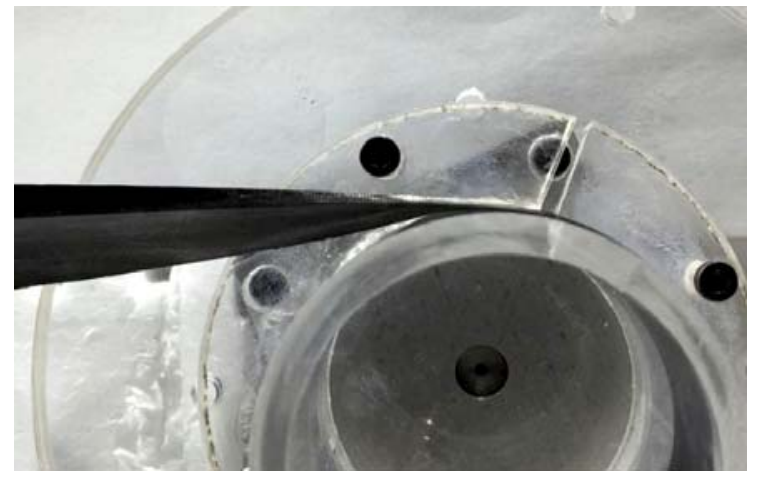

(a) Side view

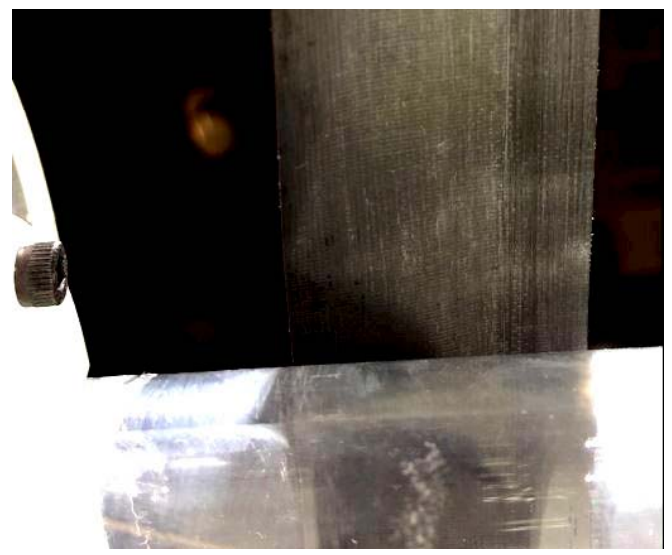

(b) Bottom view (web is on the right)

Figure 5. Buckling of the inner flange during coiling $(25.4 \mathrm{~mm}$ hub radius $)$.

over the $R=25.4 \mathrm{~mm}$ hub. Boom 4-3 exhibited a single crack after coiling around the larger hub, and multiple cracks after coiling around the $R=25.4 \mathrm{~mm}$ hub.

To better understand why some samples sustained failure on the largest hub and some did not, the thickness of the web was measured for each boom. A micrometer was used to measure the web thickness at two locations: top and bottom of the web, where the bottom is just above the merging region. Thickness was evaluated at multiple points along the length. Table 1 presents the average value for each sample. While the thickness at the top of the web does not vary significantly between all 4-ply samples, sample 4-2 is much thicker than the other at the bottom of the web. This explains why boom 4-2 exhibited multiple cracks after coiling around the largest hub.

Table 1. Average web thickness of TRAC boom samples measured at the top of the web and at the bottom (close to where the flanges separate).

\begin{tabular}{l|c|c|c|c} 
& $4-1$ & $4-2$ & $4-3$ & $3-1$ \\
\hline \hline Average Web Thickness (Top, $\mu \mathrm{m})$ & 160 & 171 & 178 & 130 \\
\hline Average Web Thickness (Bottom, $\mu \mathrm{m})$ & 218 & 272 & 225 & 177 \\
\hline
\end{tabular}

The measured thickness at the bottom of the web is significantly bigger than the expected thickness of $142 \mathrm{~mm}$ (twice the flange thickness). To understand the cause of this discrepancy, a TRAC boom was cut and two cross-sections were potted in epoxy. After fine polishing, micrographs were obtained using a microscope. Figure 6 shows the merging region of these two samples. In the first micrograph, the fibers are distorted, leading to a thickness of up to $400 \mu \mathrm{m}$. In the second, both flanges smoothly merge, creating a much thinner web.

As the web thickness close to the merging region correlates with observed failures, a thinner variant of the TRAC boom was tested (sample 3-1). It consisted of a 3-ply [0/90/0] laminate. The web thickness was measured with the same method, and the results can be seen in Table 1. This boom did not exhibit any cracks following coiling around the largest hub. Two cracks were found after rolling onto the $R=25.4 \mathrm{~mm}$ hub, and three cracks were observed following coiling around the smallest hub. These results are consistent with the conclusion that smaller web thickness allow coiling around smaller hubs without failure.

\section{Coiling Simulations}

\section{IV.A. Model Description}

The formation of cracks on the inner flange of the TRAC boom during coiling required a more in-depth investigation to understand the causes and possible solutions. One of the main questions to be answered was whether the damage was to be attributed to the presence of defects in the material or to the intrinsic properties of the geometry. 


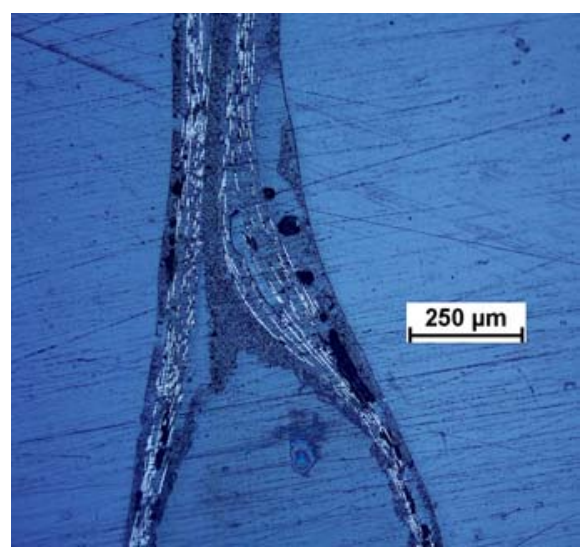

(a) Thick merging region.

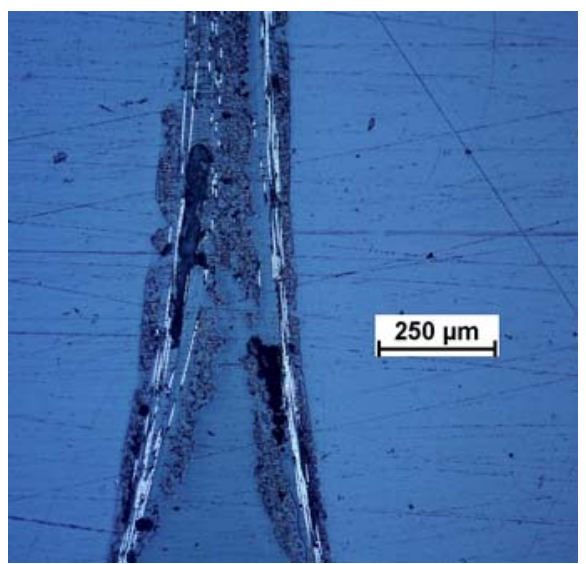

(b) Thin merging region.

Figure 6. Micrographs of TRAC boom at the location where the flanges are merging together.

For this reason, a finite element model was created using the commercial software Simulia Abaqus. The aim was to replicate the experimental setup with as much fidelity as possible, using a TRAC boom with its nominal material properties and the average geometry measured at the end of the manufacturing process (taking into account the spring-in effects).

The boom was modeled with two separate flanges, bonded together along the web with tie constraints. Each of the flanges was modeled with S4R linear shell elements, with material properties given by a $[0 / 90]_{s}$ laminate with the following lamina constants:

\begin{tabular}{c|c|c|c|c}
$E_{1}[G P a]$ & $E_{2}[\mathrm{GPa}]$ & $G_{12}[G P a]$ & $\nu_{12}$ & $\mathrm{t}[\mu \mathrm{m}]$ \\
\hline \hline 128 & 6.5 & 7.5 & 0.35 & 17.75
\end{tabular}

A cylindrical spool and a narrow clamping plate, defined as rigid bodies, reproduced the experimental setup described in Sec. III. At the other end of the boom, a constant load of $15 \mathrm{~N}$ was applied to all the end nodes, kinematically connected to a single reference point. Although in the actual experiment the load was distributed over a region of the web about $30 \mathrm{~mm}$ long, the boom was assumed long enough to obtain the same distribution of stress in the process region, independently of the distribution at the tip.

A key aspect for the accuracy of the model was the definition of appropriate contact conditions. Friction effects were not accounted for in modeling the contact between the two flanges or between flanges and the spool, for which a frictionless hard contact was defined. However, friction was used to model the clamp on the spool. This strategy was necessary to allow for flattening the cross section of the TRAC boom first and subsequently clamping it on the spool.

In order to prevent dynamic effects from introducing noise in the simulation, the whole process was modeled with a quasi-static dynamic implicit formulation. This offered a trade-off between the static implicit approach, which provides a rigorously static solution but has difficulty in converging in presence of highly nonlinear problems and complex contact conditions, and an explicit procedure, excellent at handling nonlinearities but computationally expensive for quasi-static simulations.

The analysis was structured in three steps:

- Flattening the clamped end of the TRAC boom;

- Applying the axial load at the opposite end of the boom;

- Coiling the boom by assigning an angular velocity to the spool.

The first two steps were intended to replicate the same setup as the beginning of the actual experiment, in which one of the ends of the TRAC boom was flattened and clamped on the spool by using bolts. In the FE model, flattening was performed by moving the spool and the clamp against each other, until a 
distance equal to the thickness of the two flanges was reached. To guide the process in this phase, some of the degrees of freedom of the boom were removed, by clamping the web, in order to enforce the symmetry of the flattening and prevent the occurrence of twisting effect, induced by the low torsional stiffness of the structure.

At the beginning of the second step, the nodes in the flattened region were bonded on the spool by creating a perfect frictional contact, which prevented any relative motion between the nodes of the two bodies in the contact region. This strategy allowed to model the bolts of the actual system, assuming that, at a sufficient distance from the end region, the stress distribution of the boom would be unaffected by the end effects. During this step, a tensile axial load $F_{a}=15 \mathrm{~N}$ was applied at the free end. The nodes of the web were constrained as if they were connected to an axial roller, so that they were allowed to slide axially to deform under the load, but still prevented from any other undesired motion.

In the third step, the boundary conditions on the web were removed and a constant angular velocity around the spool axis was assigned to the clamping system, which pulled the TRAC boom and coiled it in a quasi-static way.

Sensitivity analyses were performed to optimize the mesh size, finding the maximum element size able to fully capture the main features of the process.

\section{IV.B. Numerical Results}

The main outcome from FE simulations was the formation of a kink on the inner flange of the TRAC boom, in the transition region between the deployed and the coiled parts. Figure 7 shows the stress distribution in the fiber direction (material coordinates) for a TRAC boom partially coiled on a spool of radius $\mathrm{R}=$ $19.1 \mathrm{~mm}$. More precisely, the stress is extracted from the bottom face of Ply-2 for each flange (see Figure 8 for numbering conventions). On the uniformly coiled region, it is possible to recognize a small portion of the boom characterized by non-uniform stress, due to end effects. After that, the stress distribution does not vary anymore moving along the spool circumference. Along the width of the TRAC boom, it is clearly visible the presence of two different stress levels, in the flanges and in the web, with a sharp transition in between.

However, the most interesting features can be found in the transition region between the coiled and the deployed part of the boom. In particular, it is possible to recognize a kink originating at the intersection between the flanges and the web, at the first axial location in which the cross section is fully flattened. From there, it propagates at an angle of roughly $45^{\circ}$ towards the edges of the flanges, showing a pattern very similar to what was observed in the experiments discussed in Sec. III.B.

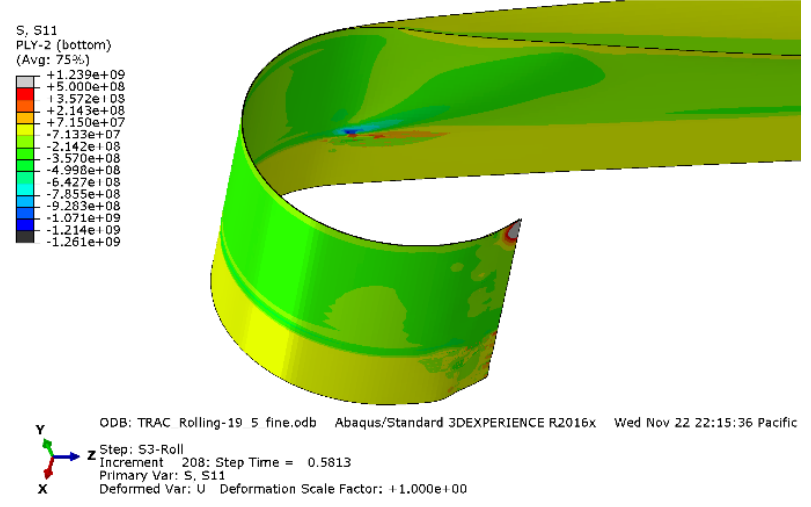

Figure 7. Stress distribution in the fiber direction on Ply-2-B for a $[0 / 90]_{s}$ laminate (see Fig. 8 for numbering convention). The radius of the spool for analysis was $R=19.1 \mathrm{~mm}$.

As a result of the kink, a stress concentration is clearly visible, with a negative peak in the order of $1000 \mathrm{MPa}$ developed in a very localized region. A positive peak of about $500 \mathrm{MPa}$ is also visible in red in the adjacent region.

To explore in more detail the behavior of the structure, the uniformly coiled region and the transition with the deployed part were studied in detail. They are discussed separately in the rest of this section.

The convention used for ply numbering is shown in Figure 8. To describe the stress distribution along the width, a normalized curvilinear coordinate was defined, with the origin on the edge of the web and the 
end at the edge of each flange.

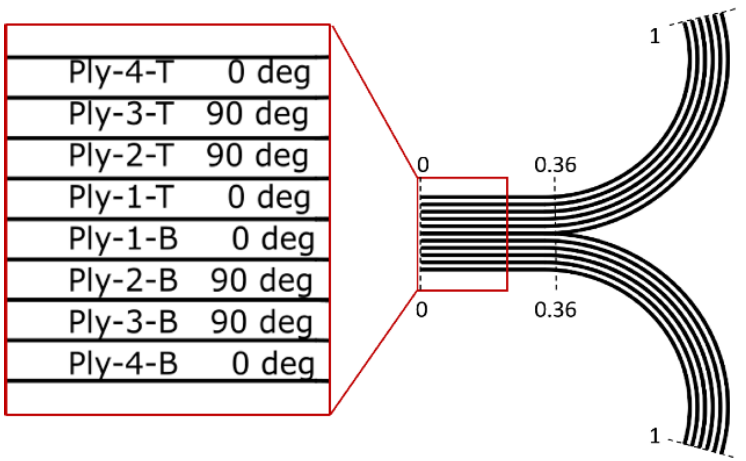

(a) 4-ply original laminate

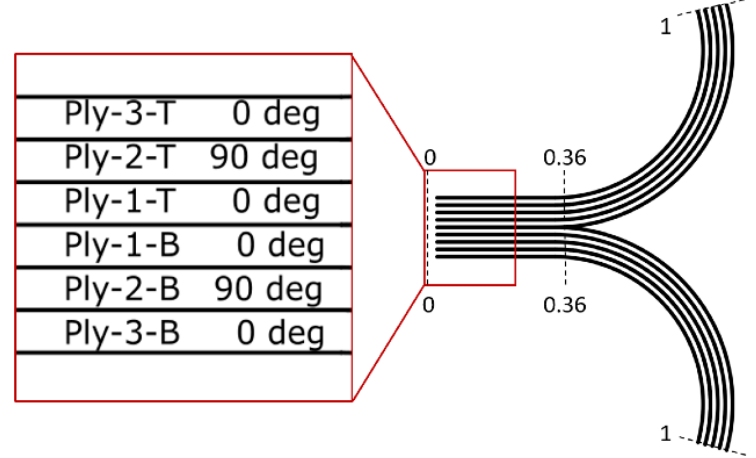

(b) 3-ply modified laminate

Figure 8. Stacking sequence and numbering convention for a 4-ply and 3-ply laminate. There are also shown the normalized coordinate in the transverse direction and the location of the transition between web and flanges.

First of all, a representative cross-section of the TRAC boom from the uniformly coiled region was chosen and the stress distribution was extracted from the centroid of each lamina, for both flanges. The results are shown in Figure 9 and 10, where the plots on the left-hand-side refer to the lower flange (which is directly in contact with the spool), while the others describe the behavior of the upper flange. The stresses are referred to the structural frame, with the $\mathrm{x}$-axis along the axis of the boom, the $\mathrm{y}$-axis along its width and the z-axis in the direction normal to the shells.

From here, it is possible to extract useful information, some of which are expected and could also be predicted by analytical calculations, others are less obvious and give an insight on the behavior of the TRAC boom, in relation to its geometry.

For example, the distribution of stress is far from uniform across the width of the boom, since the figures show the existence of two different regions, web and flanges, with different behavior, but approximately constant stress within each of them. This non-uniformity derives from the fact that the two regions differ both for material properties and loading conditions. The flanges consist of two separate 4-ply laminates, bonded together in the web, and thus forming a single 8-ply laminate. Secondly, during coiling, the web is subject only to a longitudinal change of curvature, while the flanges experience an additional change of curvature in the transverse direction, with opposite signs between top and bottom flanges.

From these considerations, the behavior of the two regions can be predicted by analytical calculations, using the Classical Lamination Theory, which shows a good agreement between theory and simulations, as it will be discussed in more detail.

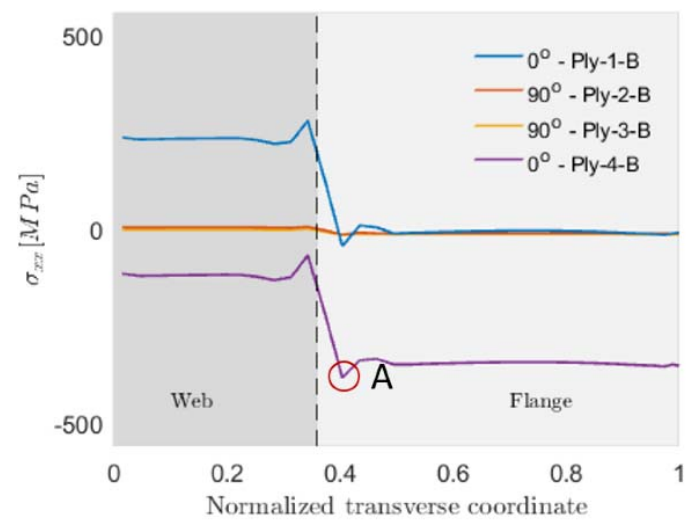

(a) Lower flange - Fiber direction

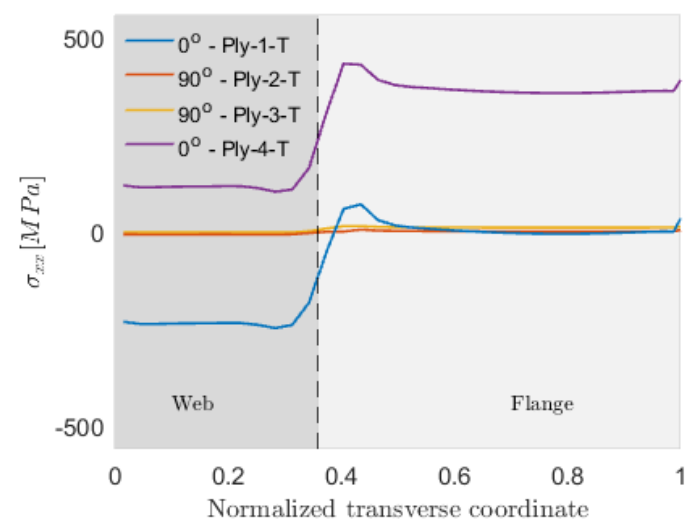

(b) Upper flange - Fiber direction

Figure 9. Stress distribution at the centroid of each lamina along a cross section in the coiled region (See Fig. 8 for ply numbering and reference frame conventions). The radius of the spool is $R=19.1 \mathrm{~mm}$. Point $A$ is the location of the maximum stress in the bottom flange, from which the through-thickness distribution is extracted in Fig. 11. 


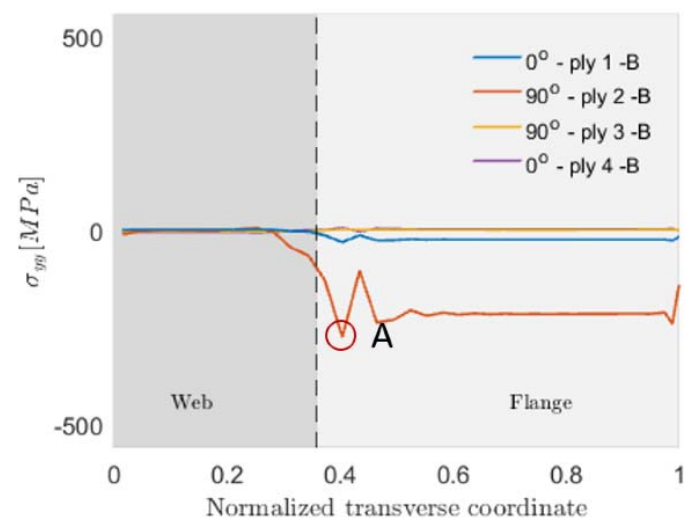

(a) Lower flange - Transverse direction

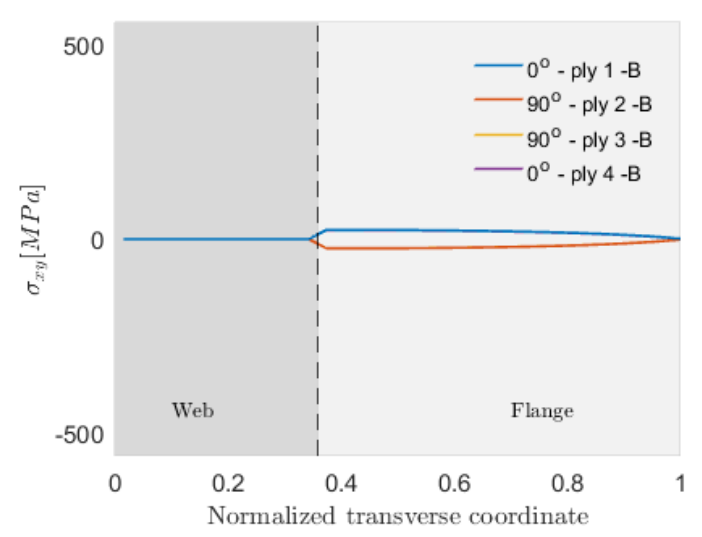

(c) Lower flange - In-plane shear

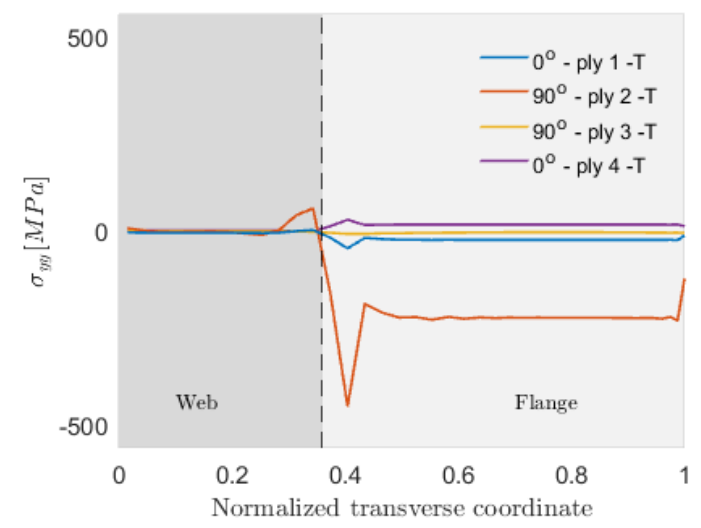

(b) Upper flange - Transverse direction

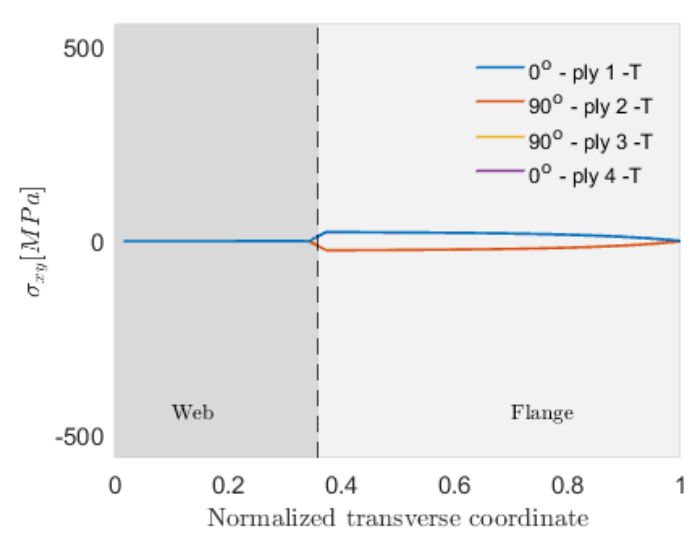

(d) Upper flange - In-plane shear

Figure 10. Stress distribution at the centroid of each lamina along a cross section in the coiled region (See Fig. 8 for ply numbering and reference frame conventions). The radius of the spool is $R=19.1 \mathrm{~mm}$. Point $\mathrm{A}$ is the location of the maximum stress in the bottom flange, from which the through-thickness distribution is extracted in Fig. 11.

The plots in Figures 9 and 10 also highlight the presence of a transition region between flanges and web, characterized by large gradients of stress and higher peaks, that cannot be described in terms of standard theories.

This phenomenon could be attributed to two main reasons: firstly, this region is dominated by the transition between the 8-ply web and the two 4-ply flanges. Although they are already split at the location in which the perturbation occurs, they are still influenced by the web and are not fully independent of each others; the second cause is related to the loading conditions, since the transition region connects two shells with a constant, but different, change of curvature. This leads to a mismatch in the stress distribution that would be found if web and flanges were not connected, thus requiring an additional perturbation stress field to guarantee the equilibrium of the shells at their shared edge. ${ }^{13}$

These two phenomena are therefore responsible for the deviation of the normal stress from theoretical values and the presence of a non-zero shear stress in the flange, which would not otherwise be expected for a cross-ply laminate.

To assess the severity of the edge effect and the amount of stress concentration induced, the throughthickness stress distribution at the peak was extracted and compared with the theoretical value, correspond- 
ing to the case in which each flange was subject to the two changes of curvature:

$$
\begin{aligned}
& \Delta \kappa_{x}=\frac{1}{R} \\
& \Delta \kappa_{y}= \begin{cases}-\frac{1}{r}, & \text { lower flange } \\
+\frac{1}{r}, & \text { upper flange }\end{cases}
\end{aligned}
$$

where $R$ is the radius of the spool and $r$ is the radius of curvature of the flange. For the specific geometry under consideration, the values are $r=10.4 \mathrm{~mm}$ and $R=19.1 \mathrm{~mm}$.

From Figure 11a, it could be observed that theory and simulations are in good agreement for the distribution of longitudinal stress, if the calculation is done by considering the mid-plane of the web as reference mid-plane for both flanges. In other words, the longitudinal load on the flanges is the same as if they were bonded together in the web, with the upper flange subjected to a tensile stress and the lower flange to a compressive stress. Therefore, this confirms that, since the through-thickness distribution was extracted from the portion of the flanges close to the interface with the web, this region is still strongly affected by the web itself.

In the transverse direction (Figure 11b), it was possible to predict the through-thickness distribution by considering each flange bent independently about its midplane, with $\Delta \kappa_{y}$ of opposite signs for top and bottom. This implies that, in this direction, the flanges behave as actually independent, although the stress distribution at this point is in some respects affected by the edge effects in terms of mean values with respect to the end of the flanges.

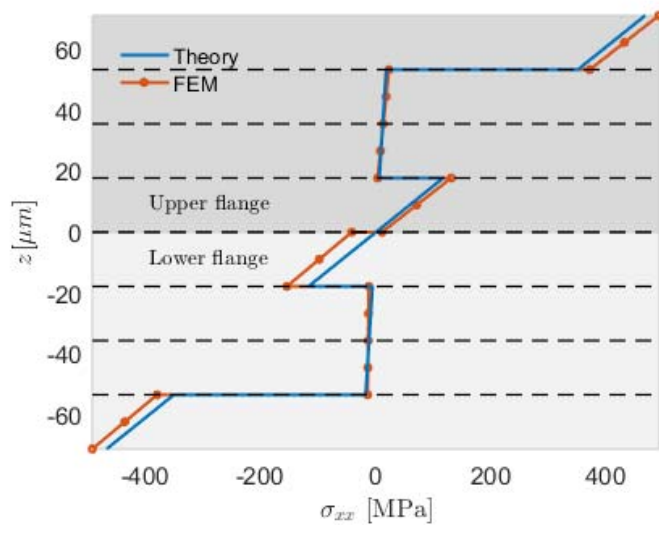

(a) Longitudinal normal stress

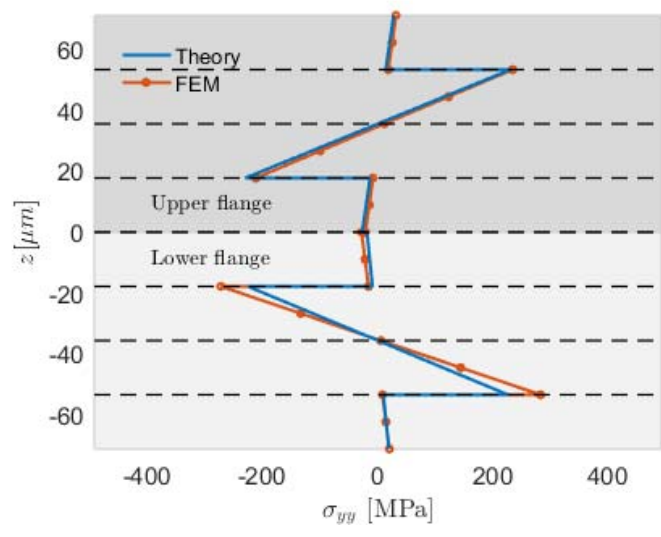

(b) Transverse normal stress

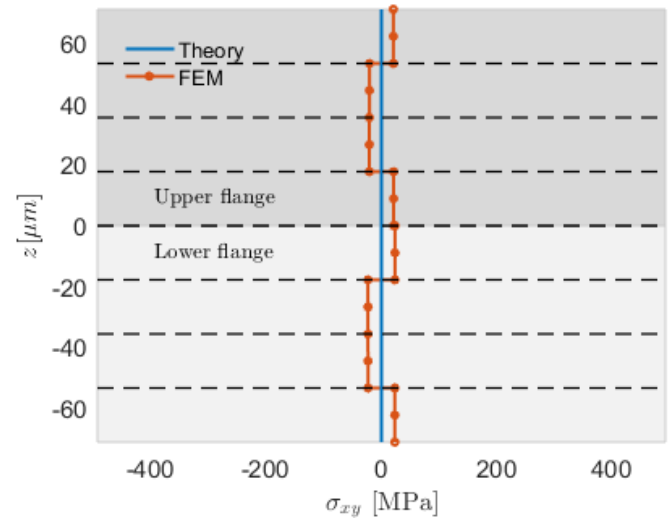

(c) In-plane shear stress

Figure 11. Comparison between analytical solution and FE simulations of through-thickness stress distribution at the peak of stress of the flanges, in the uniformly coiled region (point A from Fig. 9). The radius of the spool is $R=19.1$ mm. 
Finally, as it was anticipated before, the presence of in-plane shear stress (Figure 11c) could not be predicted by analytical calculations, and it has to be attributed to the complex interaction between flanges and web in the transition region.

In conclusion, the analysis of the uniformly coiled region of the TRAC boom highlighted the presence of stress concentrations in the material, inherently induced by the geometry of the cross section.Despite the nonuniform stress distribution discussed so far, the peak values observed should not lead to the failure of the material, according to a preliminary failure analysis. Therefore, it was necessary to study in more detail the transition between the deployed and the coiled region of the boom, where the FEM analyses in Fig. 7 showed the maximum compressive stress. Unlike the previous case, the stress distribution is not symmetric between the two flanges, and the lower one experiences much higher stresses than the upper one.

Since the deformation of the cross section is not uniform, the stress is not constant in web and flanges. In addition to this, the perturbation of the stress field in the transition between the two regions is much more severe than in the uniformly coiled region, reaching values of longitudinal stress of about 2 times the previous case. However, the highest stress is found in the transverse direction, where the peak at the centroid of the $90^{\circ}$ laminas reach a negative value of about $-600 \mathrm{MPa}$ (Figure $7 \mathrm{c}$ ).

The through-thickness stress distribution was then extracted at this point and it is shown in Fig. 14. The plots confirm that the stress concentration is confined to the lower flange and, in particular, is confined to the $90^{\circ}$ plies, with a maximum tensile stress of about $1000 \mathrm{MPa}$ and a maximum compressive stress of about $-1200 \mathrm{MPa}$.

As it will be discussed in more detail in the next section, the values are very likely to exceed the strength of the fibers and are compatible with the failures observed in the experiments.

The main conclusion to be drawn from the stress analysis is that, in the transition region between deployed

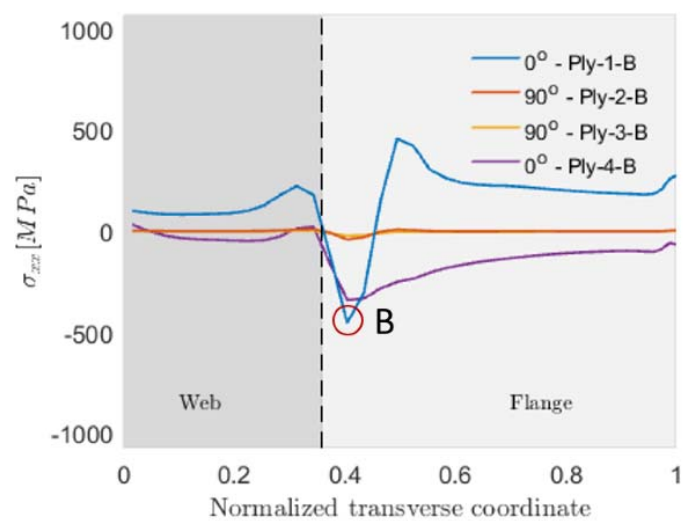

(a) Lower flange - Fiber direction

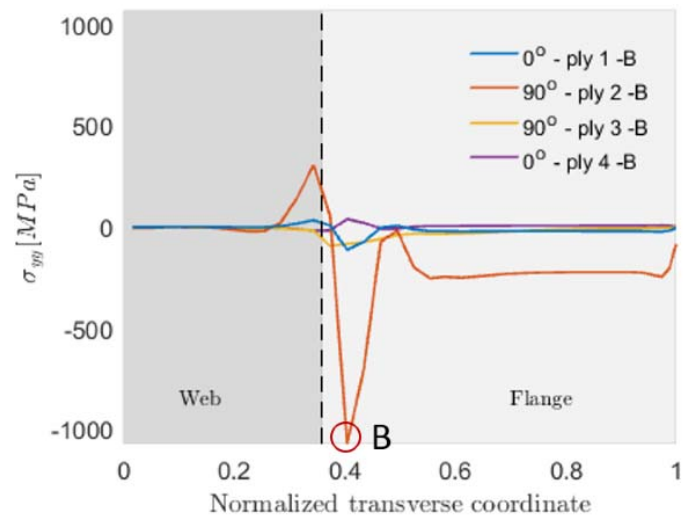

(c) Lower flange - Transverse direction

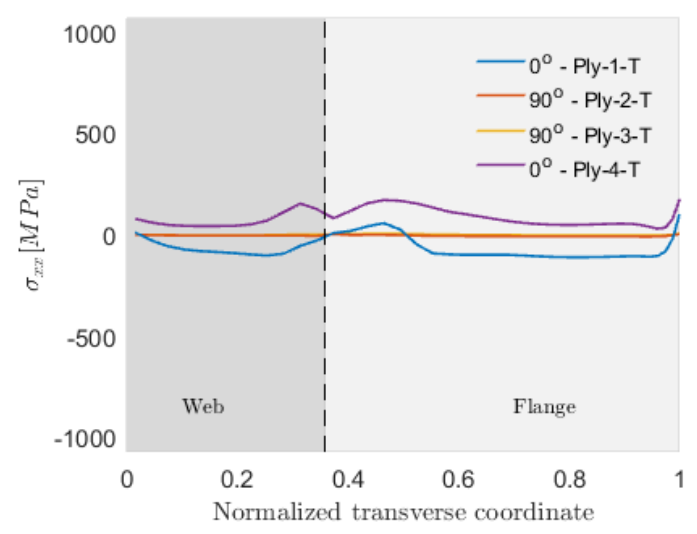

(b) Upper flange - Fiber direction

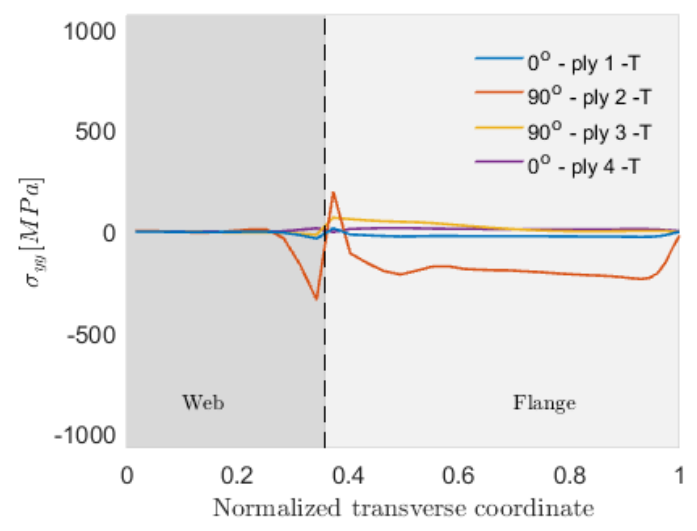

(d) Upper flange - Transverse direction

Figure 12. Stress distribution at the centroid of each lamina along the cross section in the transition region, where the kink occurs. The radius of the spool is $R=19.1 \mathrm{~mm}$. 


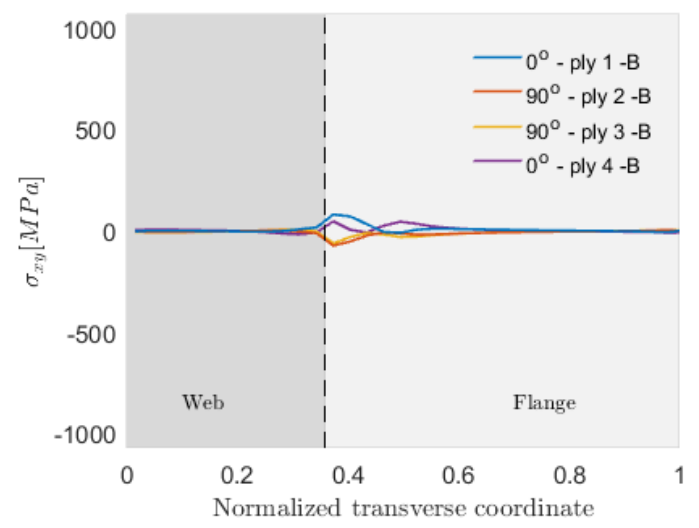

(a) Lower flange - In-plane shear

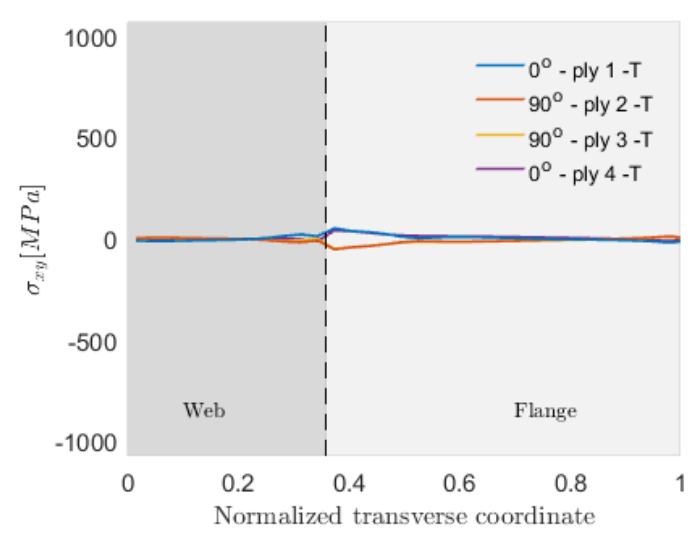

(b) Upper flange - In-plane shear

Figure 13. Stress distribution at the centroid of each lamina along the cross section in the transition region, where the kink occurs. The radius of the spool is $R=19.1 \mathrm{~mm}$ (continued).

and coiled part of the TRAC boom, flattening of the cross section leads to the formation of a kink in the transverse direction, characterized by significant localized changes of transverse curvature. As a result, very high stress occurs in the laminas with fibers oriented in the $90^{\circ}$ direction. This effect is possibly coupled

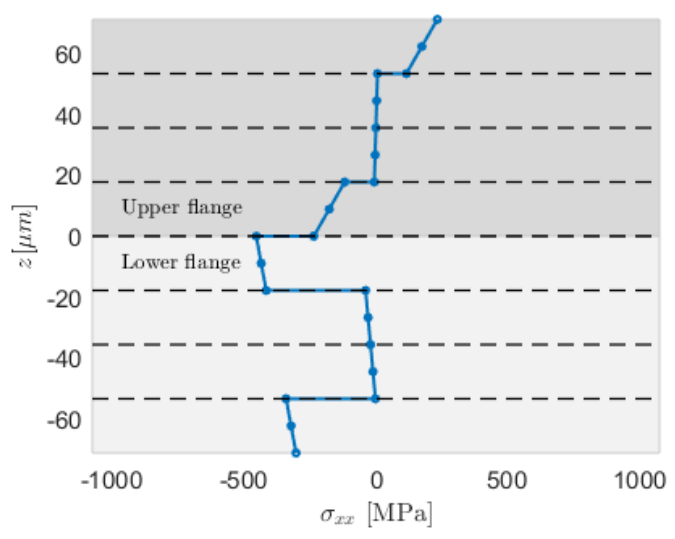

(a) Longitudinal normal stress

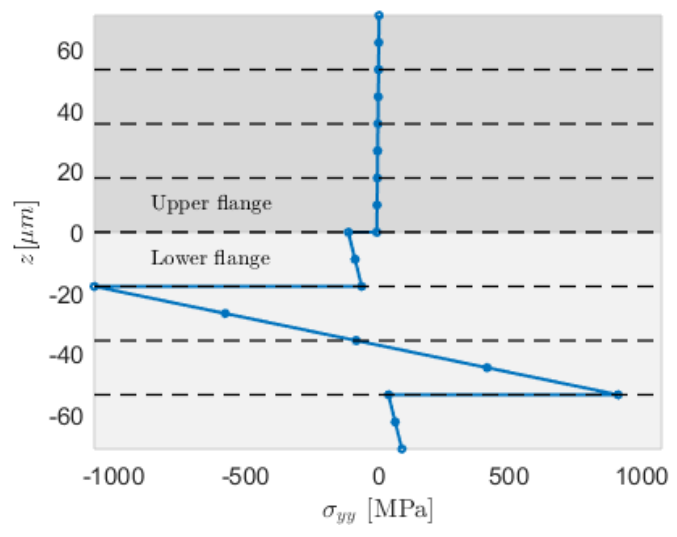

(b) Transverse normal stress

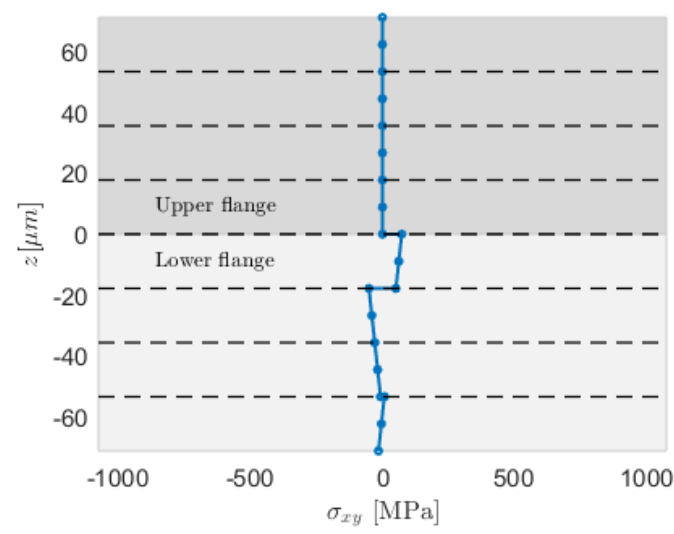

(c) In-plane shear stress

Figure 14. Through-thickness stress distribution at the peak of stress in the transition region for a 4-ply laminate (point $B$ from Fig. 12). The radius of the spool is $R=19.1 \mathrm{~mm}$. 
with the predisposition of the TRAC boom to have stress concentration at the interface between web and flanges, as already discussed before. It is not clear whether the kink was induced by the stress concentration or if it resulted from the coiling process and was only dependent on the geometry, but it is evident that this feature greatly amplifies the stress concentration, potentially leading to the failure of the material.

Moreover, FE analyses with spools of different radii showed that the maximum stress experienced in the transition region also depends on the longitudinal change of curvature imposed by the spool, as it is shown in Figure 15.

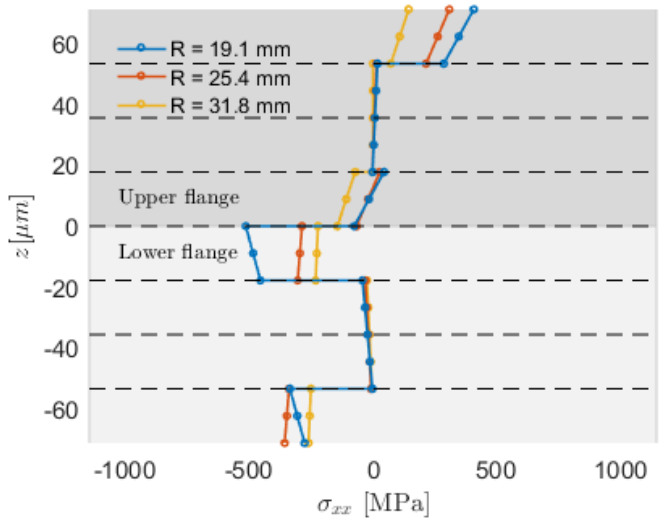

(a) Longitudinal normal stress

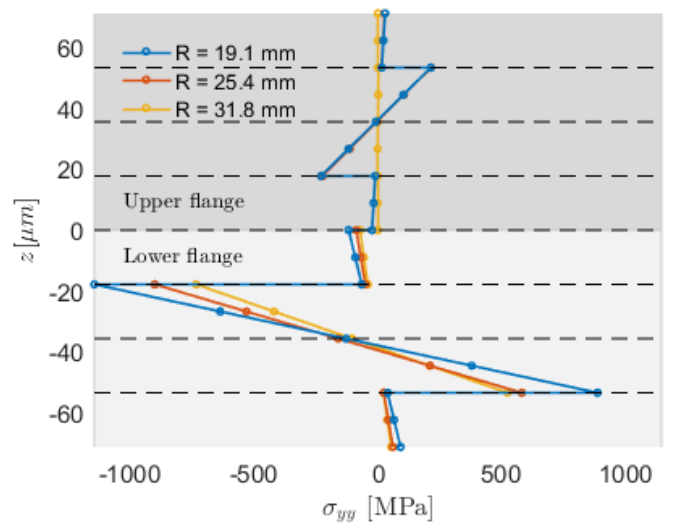

(b) Transverse normal stress

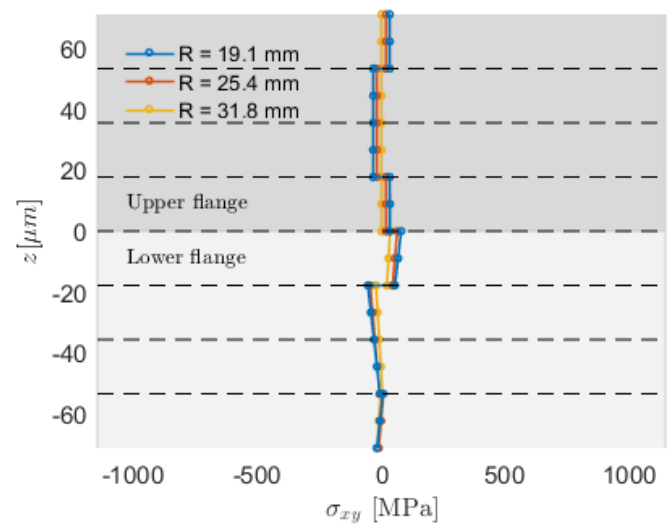

(c) In-plane shear stress

Figure 15. Through-thickness stress distribution at the kink of a 4-ply laminate, for different radii of the spool.

From these results, it can be seen that the overall distribution is qualitatively the same in all the 3 cases examined, but the maximum stress increases when decreasing the packaging radius.

\section{IV.C. Analysis of Modified Laminate}

The previous section has dealt with the numerical stress analysis of coiling of a TRAC boom and highlighted the formation of a kink in the transition region between the deployed and the uniformly coiled section, characterized by significant transverse stresses.

The possible solutions to this phenomenon involve either modifying the geometry or the material.

Since the geometry of the TRAC boom used for the present study was the result of a previous optimization, ${ }^{9,14}$ it was decided to keep it unchanged.

Therefore, the most reasonable solution was to modify the stacking sequence in order to reduce the maximum stress experienced by the material. In this respect, since the critical point was located on the $90^{\circ}$ laminas, changing the initial $[0 / 90]_{s}$ laminate to a $[0 / 90 / 0]$ would have reduced the thickness of the plies with fibers aligned in the transverse direction, thus potentially reducing their bending stress. 
To check the effectiveness of this solution, new FE simulations were done with the modified laminate. Figure 16 shows the through-thickness stress distribution at the location of the maximum stress in the transition region for the 3-ply laminate and several radii for the spool.

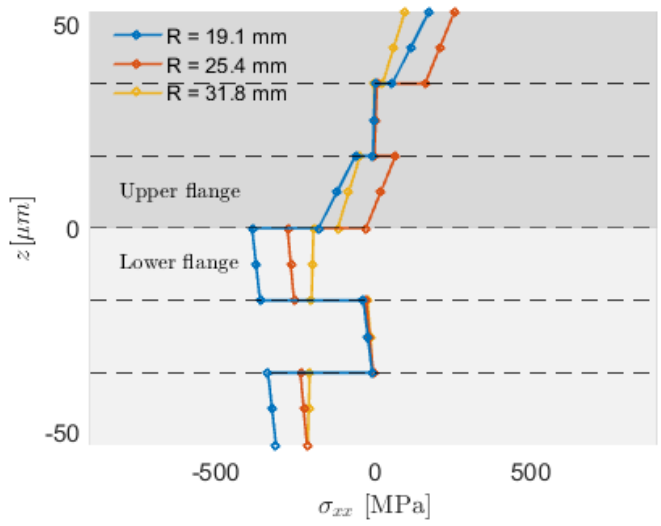

(a) Longitudinal normal stress

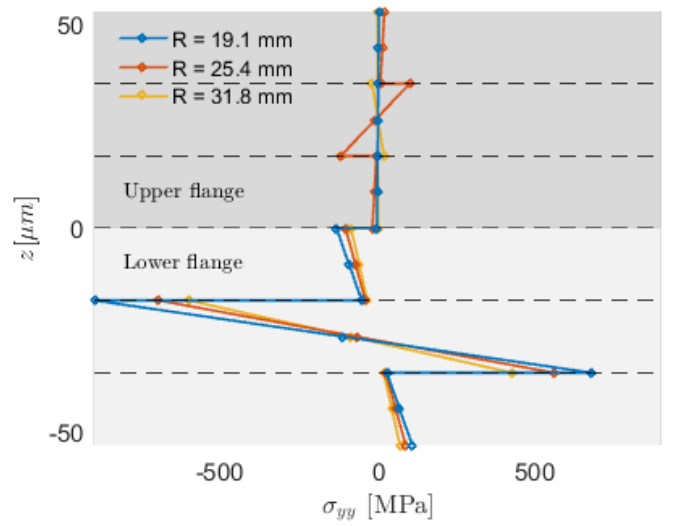

(b) Transverse normal stress

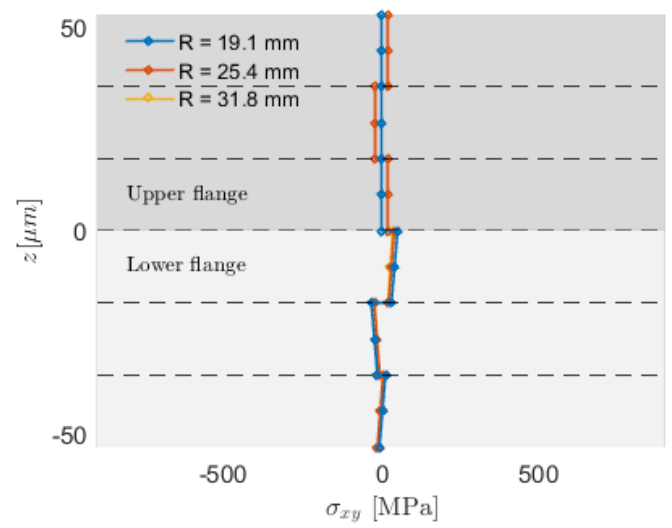

(c) In-plane shear stress

Figure 16. Through-thickness stress distribution at the kink of a 3-ply laminate, for different radii of the spool !!!!figures to be updated with new analyses!!!!

As it was expected, the maximum stress in the transverse direction is lower than it was for the 4-ply laminate, with same radius of the spool. However, reducing the thickness of the $90^{\circ}$ ply by $50 \%$ only resulted in a reduction of maximum stress by $21 \%$, which may not be sufficient to guarantee that the TRAC boom would not break during coiling.

\section{Discussion}

It has been shown that numerical tools can accurately predict inner flange buckling in the transition region between the fully deployed and coiled configurations of ultra-thin TRAC booms. The kink observed in simulations (Figure 7) agrees very well with the inner flange bulge identified during coiling experiments (Figure 5). Furthermore, the location of high stress found in simulation corresponds to the location where all material failures were observed following testing.

As the maximum stress found numerically is located in the inner flange and is compressive, a common failure mode in composite materials is fiber microbuckling, ${ }^{15}$ estimated from

$$
\sigma_{c}=\frac{\tau_{y}}{\gamma_{y}+\bar{\phi}}=\frac{G_{12}}{1+\frac{\bar{\phi}}{\gamma_{y}}}
$$

where $\gamma_{y}=\tau_{y} / G_{12}$ and $G_{12}$ is the in-plane shear modulus of the composites. Fiber misalignment was measured by Steeves ${ }^{16}$ for the same material, and values of $5^{\circ}$ were observed. Using $\tau_{y}=70 \mathrm{MPa}$ (consistent 
with values obtained for carbon/epoxy materials $\left.{ }^{17,18}\right)$, compressive failure due to fiber microbuckling is estimated to occur at $\sigma_{c}=720 \mathrm{MPa}$. Simulations predict a load peak in compression of $1200 \mathrm{MPa}$ in ply 3 -B of the 4-ply laminate, and $500 \mathrm{MPa}$ in ply 4-B. While no inspection of the inner plies was done following the current set of experiments, cracks seen on the inner flange (ply 4-B) are consistent with this estimated compressive strength.

Simulations were performed using a "perfect" TRAC geometry. However, as it can be seen in Figure 6 , the web and the region where the flanges merge into it can be significantly deformed. In some cases, the local thickness can be as much as three times the expected thickness. While no thorough investigation of the effect of these localized defects on the failure of the booms was conducted, comparison of cracking occurrence with measured web thickness shows that higher web thickness tends to increase material failure. This phenomenon could explain well the gap between the estimated compressive strength and the maximum stress obtained in simulations.

Changing the layup from $[0 / 90]_{S}$ to $[0 / 90 / 0]$ led to a reduction of compressive stress in the kink region by $21 \%$. This is consistent with experiments, where the 3-ply laminate exhibit no cracking when coiled on a hub with $R=31.8 \mathrm{~mm}$, and minimal cracking when rolled onto the $R=25.4 \mathrm{~mm}$ spool.

\section{Conclusion}

A study of the coiling behavior of ultra-thin TRAC booms has been presented. A novel procedure for manufacturing ultra-thin TRAC booms was described, where flanges are co-cured in a single step. Coiling experiments around a cylindrical hub with radius ranging between $19.1 \mathrm{~mm}$ and $31.8 \mathrm{~mm}$ showed the formation of cracks in the inner flange of the TRAC boom. Numerical simulations of the process revealed the presence of stress concentrations in the transition region between the fully deployed and the coiled parts of the structure, where both experiments and simulations confirmed the formation of a localized buckle. At this location, large gradients of curvature in the transverse direction resulted in significant stress concentrations and potential compressive failure of the material. The comparison between the peak values of stress obtained from numerical analyses and material strength estimated for failure from fiber microbuckling supported the observation that the kink is responsible for the cracking during experiments. Additionally, the effect of the radius of curvature of the packaged structure and the stacking sequence of the composite were investigated. Decreasing the thickness of the web by changing the laminate was shown to reduce stresses, allowing coiling around smaller hub without cracking.

\section{Acknowledgments}

The authors acknowledge financial support from the Northrop Grumman Corporation, the Natural Sciences and Engineering Research Council of Canada and the Keck Institute for Space Studies.

\section{References}

${ }^{1}$ Roybal, F., Banik, J., and Murphey, T., "Development of an elastically deployable boom for tensioned planar structures," 48th AIAA/ASME/ASCE/AHS/ASC Structures, Structural Dynamics, and Materials Conference, 2007, p. 1838.

${ }^{2}$ McNutt, L., Johnson, L., Clardy, D., Castillo-Rogez, J., Frick, A., and Jones, L., "Near-Earth Asteroid Scout," 2014.

${ }^{3}$ Banik, J. and Ardelean, E., "Verification of a retractable solar sail in a thermal-vacuum environment," 51st AIAA/ASME/ASCE/AHS/ASC Structures, Structural Dynamics, and Materials Conference 18th AIAA/ASME/AHS Adaptive Structures Conference 12th, AIAA, Orlando, FL, 2010, p. 2585.

${ }^{4}$ Whorton, M., Heaton, A., Pinson, R., Laue, G., and Adams, C., "Nanosail-D: the first flight demonstration of solar sails for nanosatellites," 22nd AIAA/USU Conference on Small Satellites, 2008.

${ }^{5}$ Johnson, L., Whorton, M., Heaton, A., Pinson, R., Laue, G., and Adams, C., "NanoSail-D: A solar sail demonstration mission," Acta Astronautica, Vol. 68, No. 5, 2011, pp. 571-575.

${ }^{6}$ Biddy, C. and Svitek, T., "LightSail-1 solar sail design and qualification," Proceedings of the 41st Aerospace Mechanisms Symposium, Pasadena, CA, 2012.

${ }^{7}$ Banik, J. and Murphey, T. W., "Performance Validation of the Triangular Rollable and Collapsible Mast," Proceedings of the 24th Annual AIAA/USU Conference on Small Satellites, AIAA, Logan, UT, 2010.

${ }^{8}$ Stohlman, O. R. and Loper, E. R., "Thermal deformation of very slender triangular rollable and collapsible booms," $3 r d$ AIAA Spacecraft Structures Conference, San Diego, California, 2016, pp. 2016-1469.

${ }^{9}$ Leclerc, C., Wilson, L., Bessa, M. A., and Pellegrino, S., "Characterization of Ultra-Thin Composite Triangular Rollable and Collapsible Booms," 4th AIAA Spacecraft Structures Conference, Grapevine, TX, 2017, p. 0172. 
${ }^{10}$ Murphey, T. W., Turse, D., and Adams, L., "TRAC Boom Structural Mechanics," 4th AIAA Spacecraft Structures Conference, Grapevine, TX, 2017.

${ }^{11}$ Fernandez, J. M., "Advanced Deployable Shell-Based Composite Booms for Small Satellite Structural Applications Including Solar Sails," 4th International Symposium on Solar Sailing, Tokyo, Japan, 2017.

${ }^{12}$ Leclerc, C. and Pellegrino, S., "Ultra-Thin Composite Deployable Booms," IASS Annual Symposium "Interfaces: architecture . engineering . science", Hamburg, Germany, 2017.

${ }^{13}$ Calladine, C. R., Theory of shell structures, Cambridge University Press, 1983.

${ }^{14}$ Bessa, M. A. and Pellegrino, S., "Design of ultra-thin composite deployable shell structures through machine learning," IASS Annual Symposium "Interfaces: architecture . engineering . science", Hamburg, Germany, 2017.

${ }^{15}$ Budiansky, B. and Fleck, N. A., "Compressive failure of fibre composites," Journal of the Mechanics and Physics of Solids, Vol. 41, No. 1, 1993, pp. 183-211.

${ }^{16}$ Steeves, J., Multilayer Active Shell Mirrors, Ph.D. thesis, California Institute of Technology, 2015.

${ }^{17}$ Yee, J. and Pellegrino, S., "Folding of woven composite structures," Composites Part A: Applied Science and Manufacturing, Vol. 36, No. 2, 2005, pp. 273-278.

${ }^{18}$ Odegard, G. and Kumosa, M., "Determination of shear strength of unidirectional composite materials with the Iosipescu and 10 off-axis shear tests," Composites Science and Technology, Vol. 60, No. 16, 2000, pp. 2917-2943. 